\title{
Systematic review: epidemiology of Oesophageal Cancer in SubSaharan Africa.
}

\section{Rabson Kachala}

Ritsumeikan Asia Pacific University

\section{ABSTRACT}

\section{Background}

Currently, oesophageal cancer is not a public health priority disease in Sub-Saharan Africa.

\section{Aim}

Analysis of published scientific studies regarding oesophageal cancer in Sub-Saharan Africa was done to ascertain the incidence, prevalence and geographical distribution of the disease in the region.

\section{Methods}

A pub med literature search was conducted for articles ranging from 1950 to 2009 database involving the following key words: oesophageal carcinoma, incidence, prevalence and sub-Saharan Africa.

\section{Results}

54 articles were retrieved, of which 16 were analyzed. Differences in the study methodologies used made the comparison amongst studies difficult. Overall, however, studies show that oesophageal cancer is on the increase in the region with its epicenter in the eastern and southern Africa. Incidence of the disease is higher in males than females and is prominent among 45-64 years age group in both sexes. Squamous cell carcinoma is a cell type more common than adenocarcinoma.

\section{Conclusion}

Oesophageal cancer is on the increase in the Sub-Saharan African Region with uneven geographical distribution. Therefore, countries in the region are encouraged together with global health organizations to include oesophageal cancer amongst diseases of public health importance for effective prevention, early diagnosis and effective treatment.

\section{Introduction}

Globally, IARC1 reported that oesophageal cancer was the 8th commonest cancer ${ }^{2,3}$ accounting for 462,000 new cases \& 6th commonest cause of cancer deaths worldwide in 20021 . In developing countries, it was the 5 th commonest cancer ${ }^{4}$, while in Sub-Saharan Africa, 15,150 cases in males \& 7,200 cases in females were estimated to occur in $2002^{1,5}$. It is interesting to note that other types of cancers common in the region are Kaposi's sarcoma and cancer of cervix ${ }^{6,7}$ which are prioritized indirectly by provision of some resources towards them from well concerted efforts of the governments in the region together with development partners through global support against communicable diseases which are their aetiological factors, HIV/AIDS and HPV, respectively. On the other hand, cancers which are not associated with communicable carcinogenic agents like oesophageal cancer are left in the dark, consequently, unprioritized.

During the pre-independence of African countries, there were three marked perculiarities of oesophageal cancer reported, namely; geographical distribution, vagaries of the sex ratio, and changing pattern of incidence with time $^{8}$. In the Sub-Saharan African Region, oesophageal cancer is a disease commonly diagnosed at a late stage with poor prognosis and limited treatment leading to a high case fatality rate despite some countries having the state-of-the-art specialized cancer centres in the region ${ }^{2,3,8,9}$. Surprisingly, the disease had received low priority for health care services in the region. This is attributed to the fact that the health sector in the region is obscured by poverty and communicable diseases and also because most of the data on cancer is incomplete and anecdotal. For instance, in 2002 it was only the Republic of South Africa and Mauritius in the region which submitted the data of cancer mortality to the $\mathrm{WHO}^{2,3}$. Fortunately there is a global call to improving health information on cancer through population $\&$ health research which might vindicate the extent of burden in terms of morbidity and mortality caused by these other cancers for health policy consideration. Consequently, there is a good African political will elucidated by the 14th African Union Summit in Addis Ababa, Ethiopia which was conducted from January 25th to February 2nd, 2010, under the theme: "Information and Communication Technology in Africa: Challenges \& Prospects for Development "10 where health information technology was included as a tool for planning and development for the continent.

Various countries in the Sub-Saharan African Region had established national or hospital based cancer registries and population based cancer registries from where different disaggregated studies on oesophageal cancer have emerged. However, the following question still remained unanswered as a region: "To what extent is esophageal cancer a burden in the Sub-Saharan African Region in terms of incidence and prevalence?" Therefore, this paper attempts to aggregate and analyze published scientific data and anecdotal studies on esophageal cancer in the Sub-Saharan African Region in order to ascertain the incidence, prevalence and geographical distribution of the disease in the region for evidence-based public health priorities.

\section{Study Area}

Sub-Saharan Africa is a region with countries lying below the Sahara Desert. It comprises of 46 countries out of the 53 African Member States (Figure 1) which are among countries in the world with worst health and socioeconomic indicators. For instance, average life expectancy at birth in the region in 2008 ranged from 59.49 years in Ghana to 31.99 years in Swaziland, excluding Sub-Saharan African island countries ${ }^{11}$.

\section{Methods}

This study was an epidemiological research using systematic literature review approach. A pub med search was conducted from 1950 to 1999 database, limited to English language using the following MeSH key words: oesophageal carcinoma, black population, upper digestive tract endoscopy, barium swallow, 
incidence, prevalence and Sub-Saharan Africa. To increase the searching power, some of the relevant references from the satisfying studies were added key words in order to get some details or primary data. Studies on specific occupation groups like gold miners in South Africa and copper miners in Zambia were excluded to limit confounding factors. To be included in the main analysis, population gender based and age group standardized data must have been described explicitly and the incidence or prevalence rates had to be reported per specific unit time (week, month or year). However, diagnostic inclusion criteria included both clinical investigation diagnosis [radiological (barium swallow) and upper tract endoscopy] and histology based diagnosis confirmation.

\section{Results}

The number of published studies on epidemiology of oesophageal cancer in the Sub-Saharan Africa retrieved was relatively small, 54 articles, covering 1950 to 2004 and their time denominators were not always comparable. Only 16 studies satisfied the inclusion criteria.

The overall trend of the oesophageal cancer under the period of study showed a steady increase in the population based age-gender standardized incidence rates, ranging from 0.6 cases to 76.6 cases per 100,000 males and 0.8 cases to 36.5 cases per 100,000 females from 1950 to 2002. The Republic of South Africa registered the highest incidence of 76.5 cases per 100,000 males and 36.5 cases per 100,000 females while lowest incidence was recorded in the West African countries. Mali registered the lowest incidence rate in females with 0.8 cases per 100,000 females and Guinea had the lowest male incidence rate of 0.6 cases per 100,000 males.

However, most of the data in the Sub-Saharan African Region was not always consistently accessible to show continuity. The few studies which showed continuity using the same methodologies could be depicted from Kenya, Republic of South Africa, Uganda and Zimbabwe. For instance, in Ugandan studies the oesophageal cancer incidence ranged from 1.7 cases to 15.4 cases and 2.6 cases to 14.2 cases per 100,000 males and females, respectively with specific disaggregated rates per stratified periods of 1960-1966, 1967-1971, 1991-1994, 1995-1997 of 1.7, 5.1, 15.8, 13.0 and 2.6, 7.9, 9.4, 14.2 cases in males and females, respectively (Figure 2). There was a sharp decline in age-male specific incidence rate from 15.8 cases to 13.0 cases per 100,000 male populations between 1991-1994 and 1995-1997 age groups. However, data from 1972 to 1990 could not be retrieved.

The median age of the oesophageal cancer patients in the region at diagnosis was 59 years with a range spanning from 20 years to 96 years. The disease was prominent amongst $45-$ 64 years age group across the region in both sexes with 3\% and $7 \%$ of patients with unknown ages in males and females, respectively (Figure 3).

On average, the regional studies showed a 2:1 male gender predominance influence on incidence and prevalence of the disease during the period under study, although two countries, Uganda in east Africa and Guinea in west Africa showed a minor female predominance (Table 1). Geographical distribution of the disease showed that the population in the southern and eastern African Sub-Regions had far much higher age-gender standardized incidence and prevalence rates, averaging ten times more than their counterparts in the western African Sub-Region (Table 1). There was not enough data to disaggregate the cell types of esophageal cancer to show their trend over the study period but anecdotal reports showed that squamous cell carcinoma was more common than adenocarcinoma.

\section{Discussion}

Oesophageal cancer had been a known health problem since the pre-independence era in the Sub-Saharan African Region $^{5}$. The epidemiologic aspects of oesophageal cancer are well known although the it's aetiology is known to be complex and composed of multiple factors, those caused by the environment being of greatest importance ${ }^{2,3}$. The risk factors for specific cell type of oesophageal cancer are also well established and vary dramatically for squamous cell carcinoma and adenocarcinoma. Risk factors for oesophageal squamous cell carcinoma include, smoking, excessive alcohol consumption and poor diet but is also associated with consumption of extremely hot beverages and infection with helicobacter pylori $2,3,12,13,14,15,16$. In Africa, epidemiologic studies have implicated smoking, excessive alcohol consumption, poor diet and consumption of foods contaminated with fungal elements from fungal species like Fusarium verticilliodes and Fusarium moniliforme ${ }^{3,16}$. On the other hand, risk factor for oesophageal adenocarcinoma include Barrett's oesophagus, smoking and obesity but is also associated with history of gastro-oesophageal reflux disease, hiatus hernia and p53 gene mutation ${ }^{17}$. Therefore, the majority of the factors so far implicated in oesophageal cancer aetiology appear to act directly on the oesophagus rather than systemically. However, more arguments in this paper would be biased towards risk factors of squamous cell type of oesophageal cancer than those of other cell types because anecdotal reports during the period of study showed over $95 \%$ predominance of squamous cell carcinoma.

\section{Incidence Trends of oesophageal in SubSaharan African Region}

Studies under the period of study showed in general a steady increase in population based age gender standardized disease incidence and prevalence rates. This is in line with studies done in America $^{12}$, Europe $^{18}$ and Asia ${ }^{19,20,21}$. However, most of the data in the Sub-Saharan African Region were not always consistently accessible to show continuity. The few studies which showed continuity using the same methodologies could be depicted from Uganda, Zimbabwe, Republic of South Africa and Kenya. For instance, the cumulative increase of the disease incidence rates from the stratified periods of 1960-1966, 1967-1971, 1991-1994 and 1995-1997 were statistically significant in both sexes ranging from 1.7 cases to 15.8 cases per 100,000 males and 2.6 cases to 14.2 cases per 100,000 females in Uganda (Figure 2). The average incidence rate of oesophageal cancer in the region, therefore, has shown that the estimated incidence by the GLOCAN 2002 series International Agency for Research on Cancer and National Cancer for Biotechnology Information were under estimated $^{1,22}$. The reasons attributed to this increase in the region could be explicated as due to improvement in disease diagnosis by health care providers, improvement in healthseeking behaviour of the people for modern medicine in comparison to traditional medicine, changes in the people's lifestyles opting for westernized life and endemic poverty. 
Improvement in oesophageal cancer diagnosis and health-seeking behaviour of the African People

It is a known fact that during the initial revolution of modern medicine in Sub-Saharan Africa, there has been continuous improvement in disease diagnosis including oesophageal cancer due to advancement in medical diagnostic technology. There has been increasing numbers of medical specialists in pathology, radiologists (barium swallow) and upper gastrointestinal endoscopists in the region resulting in confirmed diagnosis and autopsy of oesophageal cancer. On the other hand, there has been an overwhelming shift of African People's health-seeking behaviour since the civilization in the region opting for modern medicine such that they prefer consulting a physician to a traditional healer. Therefore, the continuous increase in the oesophageal incidence can be partly attributed to the improved diagnosis over the cumulative increased number of clients and patients consulting physicians in the region.

\section{Changes in living lifestyles of African People}

All the countries in the region except Ethiopia were colonies of western countries, especially United Kingdom, France and Portugal before acquiring independence. As such there was, admittedly, assimilation and minor changes in the typical tradition and lifestyles of the people in the region. This has been su mounted by the fact that the changes in lifestyle is anticipated due to many opportunities of Africans to train and work in western countries as well as due to globalization whereby the western people are also working and living in Africa. The sequelae of these changes include some lifestyles which predispose the Africans to risk factors of oesophageal cancer including smoking, excessive smoking and obesity.

\section{Nutritional deficiencies}

Micronutrients deficiencies including iron, beta-carotene, vitamin $\mathrm{E}$, selenium, riboflavin, niacin, retinol and zinc have been documented to be associated with increased risk of oesophageal cancer, especially in high risk patients ${ }^{12,23}$. Nutritional deficiencies can be developed by chronic alcohol use as well as by poverty and lack of an adequate food supply. Most countries in the Sub-Saharan African Region had extreme poverty and malnutrition during the period under study which can be attributed to endemic poverty and HIV/ AIDS pandemic ${ }^{24}$. On the other hand, cereal staple foods in the region are prepared in such a way that they promote deficiency of some specific nutrients and micronutrients predisposing the consumers to a favourable pathophysiologic condition of the disease process. However, the relationship between oesophagitis or oesophageal cancer and nutritional status is not fully elucidated, but if it is determined would be helpful to suggest primary method of oesophageal cancer prevention and therefore, providing a chance of lowering the incidence of this deadly disease. Therefore, continuous research on this factor is recommended using standardized methodology for comparison at regional level.

\section{Gender influence on incidence of oesophageal cancer in SubSaharan African Region}

Overall, the studies indicated a male predominant influence of 2:1 on incidence of oesophageal cancer in the region. This is consistent with the reported studies in other hot spot areas of the disease worldwide ${ }^{25}$. Male gender in the region was an added risk factor which could be expected due to the fact that most of the known risk factors of the oesophageal cancer were to do with behaviour of smoking and excessive alcohol consumption, of which men are known to be worse consumers than their gender counterpart. Additionally, many tribes in Sub-Saharan Africa regard, particularly heavy drinking of spirits as a male prerogative ${ }^{13}$. However, some of the studies in Uganda and Guinea showed minor female-age standardized incidence rates predominance ${ }^{8,26}$ (Table 1). This isolated perculiarity can be partly attributed to the practice of poor ventilated kitchen indoor-fire-cooking customs, although epidemiologic studies on this factor are not yet published. During the period under study, most customs in the region were that house chores, including cooking was a prerogative of female gender, especially before the Universal Declaration of Human Rights by the United Nations General Assembly in 1948 being substantiated through gender equality in $2006^{27}$. Smoking is a known risk factor of oesophageal cancer because it predisposes to rapid concentration of known carcinogens, for instance hydrocarbons and nitrosamines ${ }^{14}$. Therefore, poor ventilated kitchen-fire-cooking may predispose the woman to the same carcinogens if she habitually does her house chores from childhood. However, it is a conjecture because there was no data to support this line of argument in Uganda and Guinea. Some research is needed to test the hypothesis in the specific countries mentioned.

\section{Age influence on oesophageal cancer in SubSaharan Africa}

Oesophageal cancer is substantiated to be a disease of adulthood in the region because the youngest patient recorded in cancer registries was 20 years of age and 96 years on the other extreme. There was higher percentage of females with unknown age, $7 \%$, probably due to higher illiteracy than their gender counterpart in the region during the period of study. The situation could be different now because of massive female gender empowerment activists in the region.

The disease was prominent amongst 45-64 years age group across the region in both sexes (Figure 3). This could be supporting the pathophysiology of the disease deemed to be due some minimum threshold exposure of carcinogens to trigger the process of the disease. The median age group was slightly younger in the region than figures worldwide, probably due to the relatively younger life expectancies at birth in the Sub-Saharan African Region ${ }^{11}$ which could also mean that there is worse exposure to carcinogens which trigger the disease process or there are other predisposing factors in the region precipitating the progress of the natural disease than other regions.

Geographical influence on the incidence of oesophageal cancer in SubSaharan African Region A well known unique epidemiological feature of oesophageal cancer mentioned in literature has been the uneven geographic distribution, with high incidence found within sharply demarcated geographic confines ${ }^{25,28}$. That was exactly what studies in the region had also revealed. During the period of the study, data on incidence showed that the southern and eastern sub-regions of the Sub-Saharan African Region were shown to be the hot spots of oesophageal cancer in comparison with their western counterpart (Table 1). Studies done to find out the cause of that geographical uneven distribution of the disease in the region were not conclusive. Some of the attributes mentioned can be grouped as environmenta ${ }^{12}$ and ethnic attributes with the former being sub-grouped into social environment and physical environment. 


\section{Environment}

Another factor that was studied in Sub-Saharan Africa was the environmental contribution which was postulated to be among the cause of the geographical variation of oesophageal cancer. They studied both physical and social environmental factors. Soil, water, staple foods, beer and spirits chemistry was studied for physical environment.

Studies had showed that the majority of the people in the region were consuming locally brewed spirits/beer. The perculiar process of brewing the locally-made spirits/beer predisposed the consumers to some known carcinogens ${ }^{29}$. Studies had shown contaminated spirits/beer with metallic carcinogens and various carcinogenic fungal elements $3,16,29,30$ partly due to additives in the spirit/beer and modernization of brewing local spirits/beers from clay pots to metallic pots $^{31}$.

The minerals including lead, zinc and copper as well as other compounds like polycyclic hydrocarbons and nitrosamines ${ }^{32}$ were found to be in spirits/beer above normal ranges. However, the linkage of those minerals and substances to oesophageal cancer pathophysiology was not studied in terms of concentration of them in patients in comparison with control subjects.

However, this might explain the findings of $\mathrm{Blot}^{23}$, which were later expounded on by Claudia ${ }^{12}$ in 2005 that consumption of specific alcoholic beverages, such as apple brandies, maize beer, sugar-distilled spirits and moonshine whiskeys, is associated with increased rates of oesophageal cancer. Therefore, these data compels the epidemiologists in the region to conduct an advanced and standardized epidemiologic research of physical environmental factors on oesophageal cancer incidence using comparable methodologies.

On the other hand, social environment included the behaviour and lifestyle of people in the different areas of the region which is attributed by their customs, religion and cultural values.

First, synergistic effect of heavy alcohol consumption and smoking habits which was studied to be a strong risk factor of oesophageal cancer ${ }^{12}$ could be a potential factor separating western Africa from southern and eastern Africa in terms of disparities of esophageal cancer incidence.

However, this is just a hypothetical conjecture needed to be proven with research. The data on this factor is scanty and anecdotal, therefore, unworthy of comment, although it might be very important to find out the types, methods and frequencies of smoking and alcohol consumption in various ethnic groups which may later be used as evidence based data for legislation of local cigarettes and spirit/beer in the region. Cigarettes and spirits/beer legislation policies were not known to be effected during the period of study in the region.

Second, diet that is high in red and salty meat is a known risk factor for oesophageal squamous cell carcinoma ${ }^{12,13}$. Therefore, further research on bantu-speaking tribes who traditionally and culturally live on red meat as a custom like the Zulu, Ngoni tribes of southern part of Africa and Maasai tribe of the eastern part of Africa, is indicated.

\section{Ethnicity}

Some studies done in America and Europe have elucidated the effect of racial disparities between different racies ${ }^{12,18}$. The studies in America showed disparities between American

blacks and whites where oesophageal cancer incidence rate of the former was about twice that of the latter ${ }^{18}$. This is likely to be the same amongst the Sub-Saharan African ethnic groups although Hendricks and Parker ${ }^{2}$ in 2002 in South Africa studied few patients with only oesophageal squamous cell carcinoma and displayed a lower incidence of point mutations in the p53 gene than what was described in other studies in different regions.

Gatei in $1978^{19}$ summarized his oesophageal cancer's geographical distribution study in the western, central and northern Kenya by saying that the disparities in incidence and prevalence he found among the ethnic groups in the country were unlikely to be attributed to differences in reporting of the cases nor distribution of medical facilities in the area. However, this conclusion was separately challenged in a different set up by Wapnick ${ }^{25}$ who studied the origin by birth or the feeding hospitals of cases of oesophageal cancer seen at Harare Hospital in Zimbabwe which explicated the opinion of medical tourism because the high incidence rate reported previously for cases seen in Zimbabwe was, in part, due to the relatively significant larger number of patients from the neighboring countries like Malawi and Mozambique who were admitted in various satellite peripheral hospitals in the country and were being referred to the state-of-the art hospital around that sub-region. However, there was no data to show the origin by birth or referral hospitals for the cases reported in general in all southern and eastern African Hospitals to substantiate that western African patients were being seen more in the southern and eastern African Hospitals to answer the high incidence rate of the disease in the latter sub-region.

\section{Other epidemiological factors}

Occurrence of oesophageal cancer according to site (upper, middle and lower esophagus) and cell type is not reported in this paper because most studies in the region did not disaggregate such data. It was argued that many surgeons and pathologists did not indicate the site from where the biopsy or autopsy was taken. And half of the oesophageal cancer diagnosed during the period under study which were registered in the national cancer registries or specific hospital cancer registries were done based on clinical investigations [radiological (barium swallow) and upper digestive endoscopy] without histology confirmation, especially before 1990. Obviously, the reason is likely to be because there were very few histology centres and well trained specialists by then.

Some associated risk factors deemed to also be important in the region are prevalence of helicobacter pylori infection and the habit of consuming extremely hot beverages ${ }^{15}$. However, there was not enough data to comment on.

\section{Conclusion}

Oesophageal cancer is on the increase in the Sub-Saharan African Region with uneven geographical distribution. The disease incidence is exclusively higher in the eastern and southern African Sub-regions with adult males as high-risk population. Therefore, countries of the region 
are encouraged together with global health organizations to include oesophageal cancer amongst diseases of public health importance for effective prevention, early diagnosis and effective treatment. The data from the studies also support the need for advances in early detection biomarker research and standardization of diagnostic methodologies for possibility of screening high-risk populations in the region.

\section{Acknowledgements}

The results of this paper were presented at the initial launch of MEDSYN-ASIA33 in Japan.

There was no external funding for this study. The author had no conflict of interest. However, the author appreciates the invaluable technical support and mentorship rendered from Professors Nader Ghotbi, Serik Meirmanov and Monte Cassim. Lastly but not least, my thanks are due to all the doctors, pathologists and paramedics working in Africa, whose work has made this paper possible.

\section{References}

1. Ferlay J, Bray F, Pisani P, Parkin DM. 2004. “GLOBOCAN 2002: Cancer Incidence, Mortality and Prevalence Worldwide.” Version 2.0, IARC Cancer Base 5. Lyons: IARC Press.

2. Hendricks D, Parker MI. Oesophageal cancer in Africa. IUBMB Life 2002; 53(4-5): 263- 268.

3. Linda T. The use of epidemiology, scientific data, and regulatory authority to determine risk factors in cancer of some organs of the digestive system: oesophageal cancer. Regulatory toxicology and pharmacology, 1985; 5(3): 255-275.

4. Vizcaino AP, Parkin DM, Skinner MEG. Risk factors associated with oesophageal cancer in Bulawayo, Zimbabwe. British Journal of Cancer, 1995; 72: 769-773.

5. Ferlay F, Fredd B, Max Parkin D, Paola P. Cancer in Africa. Cancer Clinical, 2005; 55: 74-108.

6. Banda LT, Parkin DM, Dzamalala CP, Liomba NG. Cancer incidence in Blantyre, Malawi 1994-1998. Tropical Medicine \& International Health, 2001; 6(4): 296-304.

7. Yohannie M, Dzamalala C, Chisi J, Othieno-Abinya N. Oesophageal cancer and Kaposi's Sarcoma in Malawi: a comparative analysis. Malawi Medical Journal, 2009; 21(2): 66 -68.

8. Wabinga HR, Parkin DM, Wabwire-Mangen F, Nambooze S. Trends in cancer incidence in Kyadondo County, Uganda, 1960-1997. Br J Cancer 2000; 82: 1585-1592.

9. Wakhisi J, Patel K, Buziba N, Rotich J. Oesophageal cancer in north rift valley of western Kenya. Afr Health Sci 2005; 5: 157-163.

10. http://www.african-union.org/root/au/index/index.html

11. http://www.nationmasters.com/cat/hea-health

12. Claudia RB, Patricia C, Kelly M, Stephen M, and Shiraz IM. Oesophageal Cancer Epidemiology in Blacks and Whites: Racial and Gender Disparities in Incidence, Mortality, Survival Rates and Histology. J Natl Med Assoc. 2005; 97: 1471-1478.

13. De Stefani E, Boffetta P, Correa P, Deneo-Pellegrini H, Mendilaharsu M, Ronco AL. Food groups and risk of squamous cell carcinoma of the oesophagus: a case-control study in Uruguay. Br J Cancer 2003; 89:1209-1214.

14. IARC (International Agency for Research on Cancer). 1986. Tobacco Smoking. IARC Monographs on the Evaluation of Carcinogenic Risks to Humans, vol. 38. Lyons: IARC Press.

- 1988. Alcohol Drinking. IARC Monographs on the Evaluation of Carcinogenic Risks to Humans, vol. 44. Lyons: IARC Press.

- 1993. Some Naturally Occurring Substances: Food Items and Constituents, Heterocyclic Aromatic Amines and Mycotoxins. IARC Monographs on the Evaluation of Carcinogenic Risks to Humans, vol. 56. Lyons: IARC Press.

- 2004. Tobacco Smoke and Involuntary Smoking. IARC Monographs on the Evaluation of Carcinogenic Risks to Humans, vol. 83. Lyons: IARC Press

15. Islami F, Pourshams A, Nasrollahzadeh D, et al. Tea drinking habits and oesophageal cancer in a high risk area in northern Iran: population based case-control study. BMJ 2009; 338: b929.

16. Sebunya TK, Yourtee DM. Aflatoxigenic Aspergilli in foods and feeds in Uganda. J Food Quality, 1990; 13: 97-197.

17. Brown LM, Blot WJ, Schuman SH, et al. Environmental factors and high risk of oesophageal cancer among men in coastal South Carolina. J Natl Cancer Inst. 1988; 80:1620-1625.

18. Bosetti C, Levi F, Ferlay J, et al. Trends in oesophageal cancer incidence and mortality in Europe. Int J Cancer 2008; 222:1118-1129.

19. Ghadirian P. Thermal irritation and oesophageal cancer in northern Iran. Cancer 1987; 60(8):1909-14.

20. Kang JY. Systematic review: geographical and ethnic differences in gastro-oesophageal reflux disease. Aliment Pharmacol Ther 2004; 20: 705-717.

21. Sung JJY. Westernization of gastrointestinal diseases in Asia. Gut 2004; 53:152.

22. http://www.ncbi.nlm.nih.gov/pubmed/15761078

23. Blot WJ, McLaughlin JK. The changing epidemiology of oesophageal cancer. Semin Oncol. 1999; 26:2-8.

24.http://www.un.org/ecosocdev/geninfo/afrec/subjindx/113hung.html

25. Wapnick S, Zanamwe LND, Chitiyo M, Mynors JM. Cancer of the Oesophagus in Central Africa. Chest 1972; 61;649-654.

26. Koulibaly M, Kabba IS, Cisse A, et al. Cancer Incidence in Conakry, Guinea: First Results from the Cancer Registry 1992-1995. International Journal of Cancer. 1997;70(1): 39-45.

27. http://unicef.org/gender/index.html

28. Newton R, Ngilimana PJ, Grulich A. Cancer in Rwanda. International Journal of Cancer. 1996; 66: 75-81.

29. Van Rensburg SJ. Epidemiologic and Dietary Evidence for a Specific Nutritional Predisposition to Oesophageal Cancer. Journal of the National Cancer Institute. 1981; 67:243-51.

30. Wabinga HR, Colebunders B, Odida M, Ocama P, Colebunders R. Risk factors for and types of oesophageal cancer. Lancet 2004; 364 : 2018.

31. Paula C. Cancer of the esophagus in Africa: A summary and evaluation of the evidence for the frequency of occurrence, and a preliminary indication of the possible association with the consumption of alcoholic drinks made from maize. Br J Cancer 1971; 25: 853- 880.

32. Oettlé AG, Higginson J. Age Specific Cancer Incidence Rates in the South African Bantu: Johannesburg 1953-1955. South African Journal of Medical Science. 1966; 31: 21-41.

33. http://www.medsyn-asia.org

34. http://www.nlm.nih.gov/mesh

35. Bah E, Hall AJ, Inskip HM. The first two years of the Gambian National Cancer Registry. Brit. J. Cancer,1990; 62: 647-650.

36. Bassett MT, Chokunonga E, Mauchaza B, Levy L, Ferlay J, Parkin D M. Cancer in the African Population of Harare, Zimbabwe in 199092. International Journal of Cancer. 1995; 63: 29-36.

37. Bayo S, Parkin DM, Koumare AK, et al (1990) Cancer in Mali, 1987-1988. Int J Cancer 45: 679-684.

38. Burrell RJW. Oesophageal cancer in the Bantu. S Afr Med J 31: 401, 1957.

39. Chokunonga E, Levy LM, Bassett MT, Mauchaza BG, Thomas DB, Parkin DM. Cancer Incidence in the African Population of Harare, Zimbabwe: Second Results from the Cancer Registry 1993-1995. International Journal of Cancer. 2000; 85(1): 54-59.

40. Gatei DG, Odhiambo PA, Orinda DA, Muruka FJ, Wasunna. A Retrospective study of carcinoma of the oesophagus in Kenya. Cancer Res. 1978: 38(2): 303-307

41. Holcombe C. Helicobacter pylori: the African enigma. Gut, 1992; 33: 429-431 (1992.

42. Hutt MSR, Burkitts D. Geographical Distribution of Cancer in East Africa: A New Clinicopathological Approach. Brit. med. J.1965; 2: 719-722.

43. Labadarios D, Walker AR, Blaauw R, Walker BF. Traditional Diets and Meal Patterns in South Africa. World Review of Nutrition and Diet. 1996; 79: 70-108.

44. Lagergren J. Adenocarcinoma of oesophagus: what exactly is the size of the problem and who is at risk? Gut 2005; 54(Suppl I).

45. Leonard O, Leiman G, Segal I, Hamilton DG, Mannella A. A Suction-Abrasive Cytology Tube for the Diagnosis of Oesophageal 
Carcinoma. Cancer, 1982; 50: 782-784.

46. McGlashan ND, Harington JS, Chelkowska EZ. Changes in the geographical and temporal patterns of cancer incidence among black gold miners working in South Africa, 1964-1996. British Journal of Cancer, 2003; 88(9): 1361 - 1369.

47. Ponsiano O, Kagimu, MM, Odida M. Factors associated with carcinoma of the oesophagus at Mulago Hospital, Uganda. African Health Sciences, 2008; 8(2): 80-84.

48. Sammon AM. A Case-Control Study of Diet and Social Factors in Cancer of the Esophagus in Transkei. Cancer. 1992; 69: 860-65.

49. Sammon AM. Carcinogens and endemic squamous cancer of the oesophagus in Transkei, South Africa. Environmental initiation is the dominant factor; tobacco or other carcinogens of low potency or concentration are sufficient for carcinogenesis in the predisposed mucosa. Med Hypotheses, 2007; 69(1): 125-131.

50. Schonland M, Bradshaw E. Oesophageal cancer in Natal Bantu. A review of 516 cases. S Afr Med J 36:1028, 1969

51. Segal LI, Reinach SG, de Beer M. Factors associated with oesophageal cancer in Soweto, South Africa. British Journal of Cancer, 1998; 58: 681-686.

52. Somdyala NI, Marasas WF, Venter FS, Vismer HF, Gelderblom WC, Swanevelder SA. Cancer Patterns in Four Districts of the Transkei Region-1991-1995. South African Medical Journal. 2003; 93(2): 144-148.

53. Sur M, Cooper K. The role of the human papilloma virus in oesophageal cancer. Pathology 1998; 30: 348-354.

54. Terry PD, Lagergren J, Wolk A, Steineck G, Nyren O. Dietary intake of heterocyclic amines and cancers of the oesophagus and gastric cardia. Cancer Epidemiol Biomarkers Prev.2003; 12: 940- 944.

Table 1: Geograpnical Distribution of Desophageal Cancer Incidence in Sub-Saharan

Africa

\begin{tabular}{|c|c|c|c|c|c|c|c|c|c|c|}
\hline & \multicolumn{4}{|c|}{ Southern Africa } & \multicolumn{3}{|c|}{ Easterm Africa } & \multicolumn{3}{|c|}{ Western Africa } \\
\hline Country & $\operatorname{RSA} A^{\prime}$ & Zimbabwe & Mulawi & IARC & Ugands & Kenya & IARC & Malif & Guinen & WRC \\
\hline $\begin{array}{l}\text { Poriod of } \\
\text { study }\end{array}$ & $\begin{array}{l}1991- \\
1995\end{array}$ & $\begin{array}{l}1905- \\
1995\end{array}$ & $\begin{array}{l}1994- \\
19 / 5 \mathrm{~s}\end{array}$ & 2000 & $\begin{array}{l}1995- \\
1997\end{array}$ & $\begin{array}{l}1997- \\
2002\end{array}$ & 2000 & $\begin{array}{l}1988- \\
1992\end{array}$ & $\begin{array}{l}1992- \\
1995\end{array}$ & 2000 \\
\hline Male & & & & & & & & & & \\
\hline ASR & 76.6 & 19.6 & 15.4 & 197 & 13,0 & 26.2 & 19.1 & 1.7 & 0.6 & 13 \\
\hline Female & & & & & & & & & & \\
\hline ASR & 365 & 9.5 & 9,3 & 70 & 14.2 & 16.7 & 8.1 & 0.8 & 3.9 & 06. \\
\hline
\end{tabular}

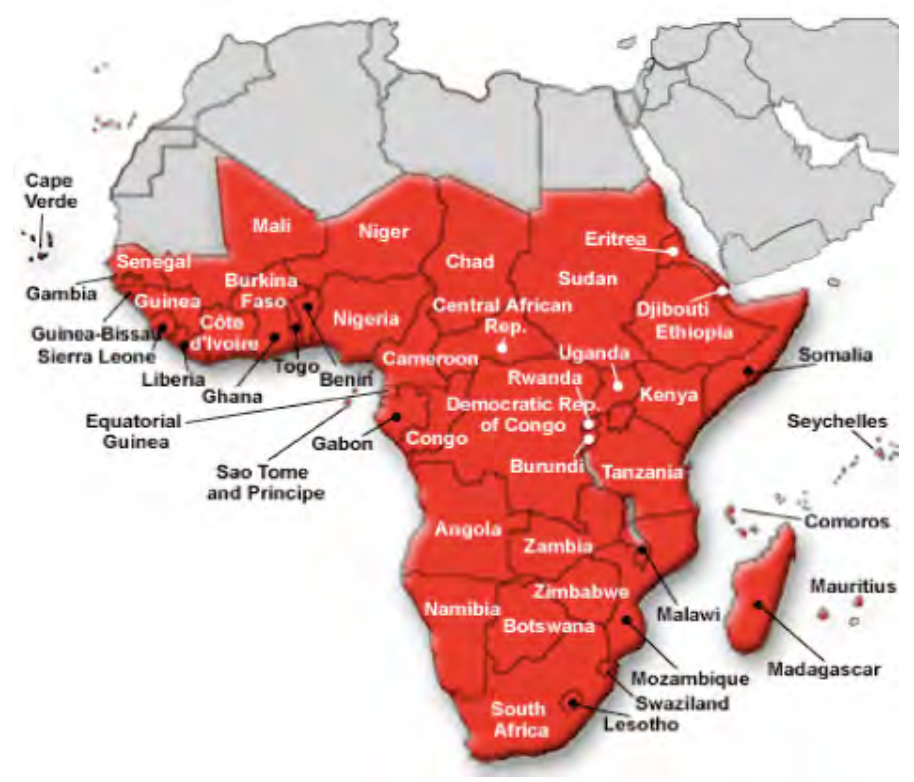

Figure 2: Trends in incidence of oesophageal cancer in uganda.

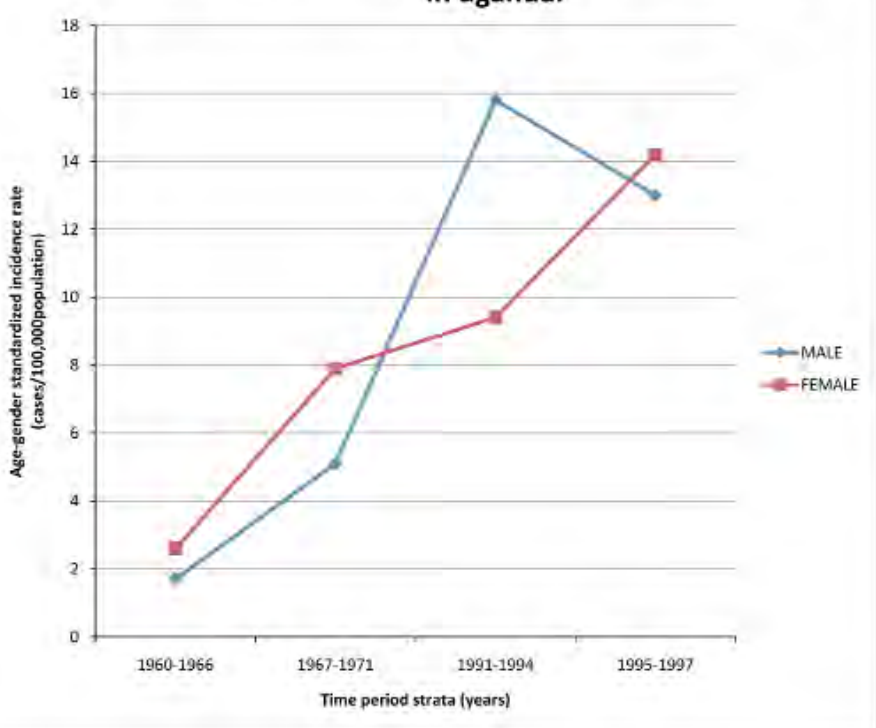

Figure 3: Age at diagnosis of oesophageal cancer in Sub-Saharan Africa from 1993 to 2002.

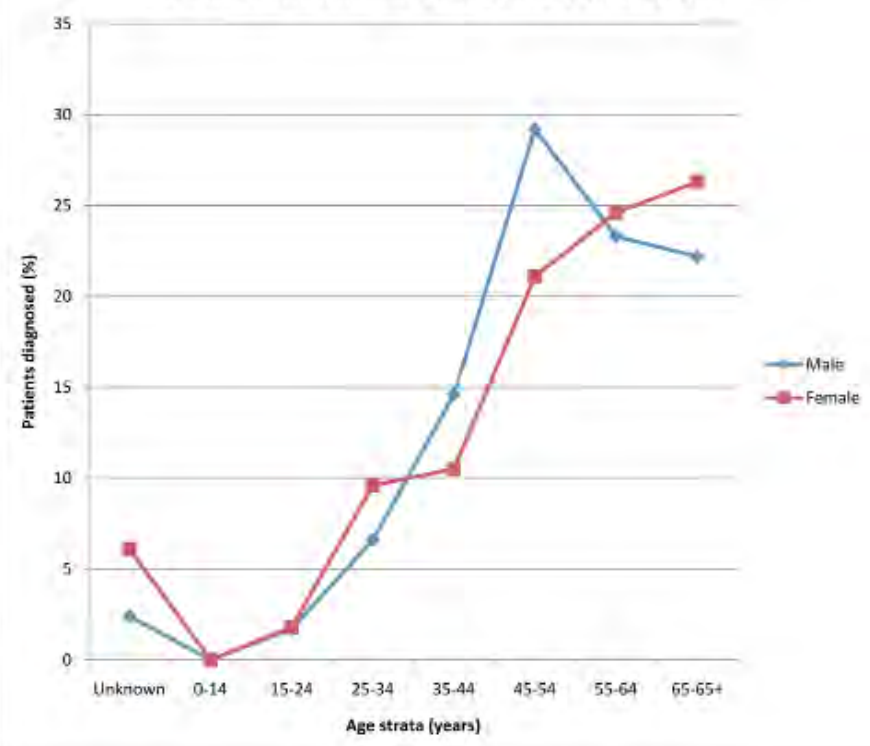

